\title{
Why pharmacokinetic differences among oral triptans have little clinical importance: a comment
}

\author{
Anna Ferrari · Ilaria Tiraferri · Laura Neri • \\ Emilio Sternieri
}

Received: 12 August 2010/Accepted: 13 September 2010/Published online: 29 September 2010

(C) Springer-Verlag 2010

\begin{abstract}
Triptans, selective 5-HT1B/1D receptor agonists, are specific drugs for the acute treatment of migraine that have the same mechanism of action. Here, it is discussed why the differences among kinetic parameters of oral triptans have proved not to be very important in clinical practice. There are three main reasons: (1) the differences among the kinetic parameters of oral triptans are smaller than what appears from their average values; (2) there is a large inter-subject, gender-dependent, and intra-subject (outside/during the attack) variability of kinetic parameters related to the rate and extent of absorption, i.e., those which are considered as critical for the response; (3) no dose-concentration-response curves have been defined and it is, therefore, impossible both to compare the kinetics of triptans, and to verify the objective importance of kinetic differences; (4) the importance of kinetic differences is outweighed by non-kinetic factors of variability of response to triptans. If no oral formulations are found that can allow more predictable pharmacokinetics, the same problems will probably also arise with new classes of drugs for the acute treatment of migraine.
\end{abstract}

\footnotetext{
A. Ferrari $(\square) \cdot$ E. Sternieri

Headache and Drug Abuse Inter-Dep. Research Centre, Division of Toxicology and Clinical Pharmacology, University of Modena and Reggio Emilia, Policlinico, Largo del Pozzo 71, 41100 Modena, Italy

e-mail: anna.ferrari@unimore.it

I. Tiraferri

School of Medical Toxicology,

University of Modena and Reggio Emilia, Modena, Italy

L. Neri

School of Clinical Pharmacology,

University of Modena and Reggio Emilia, Modena, Italy
}

Keywords Acute treatment - Disposition - Headache . Pharmacokinetics · Triptan · Variability

\section{Introduction}

The availability of many drugs for the management of a disorder should allow optimising the therapy, obtaining for individual patient maximum benefits with minimal side effects [1]. Triptans, selective agonists at 5-hydroxytryptamine $1 \mathrm{~B} / 1 \mathrm{D}$ receptor subtype, are among the few specific drugs which are effective and safe for acute migraine treatment [2]. Migraine is a very common disorder. Its lifetime incidence is $18 \%$ in men and $43 \%$ in women [3]. Although migraine is not life-threatening, it often heavily affects work and social functioning and reduces the overall quality of life [4].

The triptans are recommended as first-line drugs for patients suffering from moderate to severe migraine, associated with disability, who do not respond to COX-inhibitors [2]. Sumatriptan was the first to be marketed, at the beginning of the 1990s. Even if it is fast absorbed orally, its bioavailability is only $14 \%$ and it has a short half-life of about $2 \mathrm{~h}$. Six other triptans have been later introduced: zolmitriptan, naratriptan, rizatriptan, eletriptan, almotriptan, and frovatriptan, which have greater oral bioavailability, longer plasma half-life, active metabolites, higher lipophilicity, and greater potency and affinity for 5-HT1B/1D receptors [5]. Triptans are homogeneous in their mechanism of action [6]. It has, therefore, been thought that the differences with respect to their pharmacokinetics can cause a different efficacy, frequency of recurrence, and consistency of response, and they can therefore allow choosing the most appropriate triptan for each patient [7]. However, only minor differences in the efficacy of oral triptans for migraine have been 
Table 1 Some pharmacokinetic parameters of oral triptans

\begin{tabular}{llll}
\hline Triptan & $C_{\max }(\mathrm{ng} / \mathrm{ml})$ & AUC $(\mathrm{ng} \mathrm{h} / \mathrm{ml})$ & $T_{\max }(\mathrm{h})$ \\
\hline Almotriptan 12.5 mg [22, 54] & $49.5^{\mathrm{a}}(13.5)$ & $266.1^{\mathrm{a}}(39.1)$ & $2.5^{\mathrm{a}}(0.7)$ \\
Eletriptan 20 mg [57] & $61.5^{\mathrm{b}}(32.5-116.5)$ & $317.3^{\mathrm{b}}(152.9-658.1)$ & $1.0^{\mathrm{c}}(0.5-1.5)$ \\
Frovatriptan 2.5 mg [58] & $42^{\mathrm{b}} \mathrm{M}(3.19-5.61)$ & $42.9^{\mathrm{b}} \mathrm{M}(36.3-50.7)$ & $2.3^{\mathrm{c}} \mathrm{M}(2.0-2.5)$ \\
& $7.0^{\mathrm{b}} \mathrm{F}(6.02-8.14)$ & $65.8^{\mathrm{b}} \mathrm{F}(65.8-134.3)$ & $3.0^{\mathrm{c}} \mathrm{F}(2.0-4.0)$ \\
Naratriptan 5 mg [19,59] & $10.8^{\mathrm{d}} \mathrm{M}(7.1-14.2)$ & $108.2^{\mathrm{d}} \mathrm{M}(76.6-168.1)$ & $3.0^{\mathrm{c}} \mathrm{M}(2.0-6.0)$ \\
& $16.6^{\mathrm{d}} \mathrm{F}(9.8-37.3)$ & $163.6^{\mathrm{d}} \mathrm{F}(89.9-256.5)$ & $3.0^{\mathrm{c}} \mathrm{F}(1.0-6.0)$ \\
Rizatriptan 10 mg [20,60, 61] & $28.6^{\mathrm{a}} \mathrm{M}(13.5)$ & $72^{\mathrm{a}}(22)$ & $1.0^{\mathrm{a}}(0.5)(\mathrm{range}: 0.6-2.4)$ \\
& $32.1^{\mathrm{a}} \mathrm{F}(11.9)$ & $97^{\mathrm{a}}(28)$ & $1.2^{\mathrm{a}}(1.0)(\mathrm{range}: 0.4-2.0)$ \\
Sumatriptan 50 mg [31] & $30.1^{\mathrm{a}}(12.5)$ & $103^{\mathrm{a}}(49)$ & $0.83^{\mathrm{e}}(0.33-3.00)$ \\
Sumatriptan 100 mg [33] & $53.2^{\mathrm{a}}(29)$ & $199^{\mathrm{a}}(105)$ & $1.0^{\mathrm{e}}(0.5-4.00)$ \\
Zolmitriptan 2.5 mg [18] & $3.0^{\mathrm{a}}(1.7)$ & $17^{\mathrm{a}}(8.1)$ & $2.0^{\mathrm{c}}(0.5-6.0)$ \\
& $3.3^{\mathrm{e}} \mathrm{M}$ & $17.7^{\mathrm{e}} \mathrm{M}$ & $21.3^{\mathrm{e}} \mathrm{F}$ \\
\end{tabular}

$M$ males, $F$ Females

${ }^{a}$ Arithmetic mean $( \pm \mathrm{SD})$

${ }^{\mathrm{b}}$ Geometric mean $(95 \% \mathrm{CI})$

c Median (range)

d Arithmetic mean (range)

${ }^{\mathrm{e}}$ Geometric mean (range)

reported [5, 8]. In particular, the maximum response after oral administration, measured as pain relief after $2 \mathrm{~h}$, is approximately $70 \%$ in clinical trials [9], and up to $40 \%$ of attacks fail to respond to a particular drug [10]. Furthermore, less than $2 / 3$ of patients respond to a triptan in three out of three attacks [11]. Recurrence is a common event; in triptan trials, recurrence rates vary from 7 to $57 \%$ [12], and in patients using triptans headache return is associated to $24 \%$ of headaches which have had a pain-free response [13]. Indeed, $40-50 \%$ of patients report dissatisfaction with at least one aspect of their current triptan therapy [14], there is a marked variation in the individual patient response and preference for the available oral triptans [15, 16], and it seems that there are no characteristics which can make the difference between one drug and another [17]. Moreover, there is no clear method of choosing an appropriate oral triptan for a particular patient and, currently, this is achieved by trial and error [11].

Omitting pharmacodynamic aspects and the variability of response depending on metabolism, we have analysed here why pharmacokinetic differences among the various oral triptans have such a limited clinical importance.

\section{Because of the interindividual variability of kinetic parameters}

The differences among the kinetic parameters of the various triptans are less important than what can appear from average values (arithmetic mean, median or geometric mean) of these parameters (Table 1). There is great interindividual variability of kinetic parameters, which only emerges if, besides the average value, the standard deviation (i.e., the spread of data around the expected value), and the range of the values are also indicated. The interindividual variability is even more evident, if the coefficient of variation $(\mathrm{CV}$, allowing comparison of data sets with different unit measures) or the confidence interval (CI, i.e., an interval likely to include as a parameter) is expressed. This variability reduces the difference between a drug and another, makes the comparison among triptans difficult, and limits the possibility to predict with a good chance of success the kinetics of a certain triptan in an individual patient.

Numerous kinetic parameters of triptans vary, also in a statistically significant way, according to gender (Table 2). In particular, $C_{\max }$ (the peak plasma concentration) and $\mathrm{AUC}_{0-\infty}$ (the area under plasma concentrations from 0 to infinity) of frovatriptan, naratriptan, rizatriptan, and zolmitriptan are significantly lower in males than in females. These differences have been partially attributed to higher bioavailability in females and higher total body clearance in males [18-22]. Kinetic variations according to gender have generally received little attention from researchers also because, according to producers, no dose adjustment is needed depending on the patient's gender. This statement makes it clear the limited importance of plasma concentrations, in particular of maximum ones, as a parameter by itself, indicative of the response [23]. It also 
Table 2 Male/female ratio of the pharmacokinetic parameters of some oral triptans

\begin{tabular}{|c|c|c|c|c|c|c|c|}
\hline \multirow[t]{2}{*}{ Triptan } & \multicolumn{7}{|c|}{ Male/female ratio of pharmacokinetic parameters } \\
\hline & Bioavailability $\%$ & $C_{\max }(\mathrm{ng} / \mathrm{ml})$ & $\mathrm{AUC}_{0-\infty}(\mathrm{ng} \mathrm{h} / \mathrm{ml})$ & $T_{\max }(\mathrm{h})$ & $\mathrm{Vd}(\mathrm{L})$ & $t_{1 / 2}(\mathrm{~h})$ & CLp (ml/min) \\
\hline Almotriptan 12.5 mg [22] & NS & NS & NS & NS & - & NS & NS \\
\hline Frovatriptan $2.5 \mathrm{mg}[21]$ & 0.88 & 0.60 & $0.46^{\mathrm{a}}$ & $0.66-0.77$ & 1.66 & 1.07 & 1.64 \\
\hline Naratriptan 5 mg $[19,59]$ & 0.85 & 0.79 & 0.66 & - & - & - & 1.25 \\
\hline Rizatriptan $5 \mathrm{mg}[20,60,61]$ & - & 0.96 & 0.78 & 0.77 & 1.31 & 0.92 & 1.27 \\
\hline Rizatriptan $10 \mathrm{mg}[20,60,61]$ & - & 0.89 & 0.74 & 1.00 & 1.38 & 0.92 & 1.22 \\
\hline Zolmitriptan $2.5 \mathrm{mg}$ [18] & $1.00^{\mathrm{b}}$ & $0.87^{\mathrm{c}}$ & $0.83^{\mathrm{d}}$ & 1.54 & 1.04 & 0.90 & 1.13 \\
\hline Zolmitriptan 5 mg [18] & 0.78 & 0.62 & 0.56 & - & - & 0.92 & - \\
\hline
\end{tabular}

$N S$ no statistically significant differences, - datum not available

a $\mathrm{AUC}_{0-12}=0.63$

b $95 \% \mathrm{CI}=0.84-1.26$

c $95 \% \mathrm{CI}=0.60-1.05$

d $95 \% \mathrm{CI}=0.61-1.09$

suggests that the differences in the mean values of the pharmacokinetic parameters of triptans cannot predict a different efficacy.

\section{Because the dose-concentration-response relationship is not definite for oral triptans}

Pharmacokinetic factors will influence the disposition of a drug in the body, and ultimately, the concentration of unbound, or free, drug at the receptors, fundamental to the drug's effect. For pharmacokinetic factors to be of relevance, alterations in the concentration of drug at the receptor must cause changes in the amount of the drug effect. In other words, a dose-concentration-response relationship must be discernible. Most pharmacokinetic studies have been unfortunately carried out in healthy volunteers or migraine patients, but outside the attack. Furthermore, the responses to the triptan in migraine attack treatment are time-dependent $[24,25]$. All triptans are more effective, if they are taken early and when pain is mild [26]. Also for these reasons, plasma concentrations are not directly related to the effect and the clinical response, and the dose-concentration-response curve has not been defined for any oral triptan [25, 27, 28]. Therefore, it is impossible to compare triptans and objectively verify the importance of the differences in pharmacokinetic parameters during the migraine attack.

\section{Because few pharmacokinetic parameters can be used to compare triptans}

The changes in the plasma concentrations of the triptan in the initial phase (till $2 \mathrm{~h}$ after administering the drug) have been considered important to relate kinetics to clinical response. This phase is characterised by the extent and rate of absorption. However, the initial rate of absorption seems to be related to the patient's response more than the height of the plasma concentrations reached [28-30]. The key variable is therefore $T_{\max }$ (time to peak concentration), which indicates the rate of absorption [31]. Nevertheless, this parameter is the one which presents the highest interindividual variability. The comparison between $T_{\max }$ and therapeutic gain at $2 \mathrm{~h}$ after administering different formulations of sumatriptan (oral, rectal, intranasal, subcutaneous, and intravenous) shows the importance of this parameter. An inverse relationship has been observed between $T_{\max }$ and therapeutic gain: the fewer $T_{\max }$, the higher therapeutic gain after $2 \mathrm{~h}$ [32].

$C_{\text {max }}, \mathrm{AUC}_{0-2}, C_{\text {max }} / T_{\max }, \mathrm{AUC}_{0-2} / \mathrm{AUC}_{0-t}, \mathrm{AUC}_{0-\infty} /$ $T_{\max }$, and $C_{\max } / \mathrm{AUC}_{0-\infty}$ have also been proposed to assess the rate and extent of absorption [29, 33, 34]. However, these parameters can only be used to compare different formulations of the same triptan, and not different triptans, since data about the time-course of plasma concentrations in connection with the dose and response are missing, and we do not know the minimum effective concentrations of oral triptans which have different potency.

\section{Because of the variability of oral absorption}

An oral drug should allow, besides easy taking, an effective, fast, and predictable absorption, in order to assure a response in most subjects. In the case of triptans, with the same oral dose, plasma concentrations vary a lot from one patient to another, especially in the first phase after oral administration, i.e., the most critic one for response [35]. For example, after the administration of oral sumatriptan 
$200 \mathrm{mg}$, maximum plasma concentrations varied from 52 to $227 \mathrm{ng} / \mathrm{ml}$ in healthy volunteers [34]. Plasma levels after administering oral zolmitriptan $10 \mathrm{mg}$ in migraine patients outside the attack varied from 3 to $27 \mathrm{ng} / \mathrm{ml}$ after $2 \mathrm{~h}$ [36]. In addition, multiple peaks in plasma concentrations are found in some individuals after oral administration of sumatriptan, rizatriptan, and zolmitriptan [18, 30, 37]. The mechanism of this phenomenon has not been explained. It could be due to the different rates of stomach emptying or intestinal transit [38]. After oral administration of zolmitriptan, the time to achieve $C_{\max }$ varied from 0.5 to $6 \mathrm{~h}$, since some subjects had multiple peaks [36]. One of the factors which influence absorption is also the rate of stomach emptying, which is a unique characteristic of each individual [39]. Migraineurs have delayed gastric emptying during and between migraine attacks [40]. The variability of absorption is very likely to increase even more during the migraine attack when there is gastric stasis [41]. The absorption of any triptan during the attack can therefore be unforeseeable and erratic, and the outcome is not consistent [28, 42, 43]. During the migraine attack (Table 3), the amount absorbed and the plasma maximum concentration decrease and $T_{\max }$ increases. These changes in pharmacokinetic parameters are statistically significant or close to significance for some triptans. Since, in order to have a complete response, it is fundamental to achieve sufficient plasma levels of triptan quickly following the onset of pain, the impairment of drug absorption may be the cause of the therapeutic failure of an oral triptan. Indeed, when studying the pharmacokinetics of sumatriptan following $100 \mathrm{mg}$ oral

Table 3 During/outside migraine attacks ratio of the pharmacokinetic parameters of some oral triptans

\begin{tabular}{|c|c|c|c|}
\hline \multirow[t]{2}{*}{ Triptan } & \multicolumn{3}{|c|}{$\begin{array}{l}\text { During/outside migraine attacks ratio } \\
\text { of pharmacokinetic parameters }\end{array}$} \\
\hline & $\begin{array}{l}C_{\max } \\
(\mathrm{ng} / \mathrm{ml})\end{array}$ & $\begin{array}{l}\mathrm{AUC}_{0-\infty} \\
(\mathrm{ng} \mathrm{h} / \mathrm{ml})\end{array}$ & $T_{\max }(\mathrm{h})$ \\
\hline Almotriptan $12.5 \mathrm{mg}^{\mathrm{a}}[22,54]$ & 0.93 & 1.00 & 1.23 \\
\hline Eletriptan $40 \mathrm{mg}^{\mathrm{b}}[57,62]$ & $0.69^{\mathrm{c}}$ & $0.71^{\mathrm{d}}$ & $2.15^{\mathrm{e}}$ \\
\hline Frovatriptan $2.5 \mathrm{mg}[58]$ & $\begin{array}{l}0.93 \mathrm{M} \\
0.91 \mathrm{~F}\end{array}$ & 0.53 & 0.66 \\
\hline Naratriptan 5 mg [63, 64] & ND & ND & $1.75-2.33$ \\
\hline Sumatriptan $100 \mathrm{mg}[65,66]$ & $0.80^{\mathrm{f}}$ & - & - \\
\hline Zolmitriptan 2.5 mg $[18,36]$ & 0.75 & 0.56 & 1.6 \\
\hline $\begin{array}{l}N D \text { no difference observed, }-\mathrm{d} \\
\text { a No statistically significant diff } \\
\text { b Statistically significant differe } \\
{ }^{\mathrm{c}} \mathrm{CV}=90.2 \% \text { during attacks } \\
{ }^{\mathrm{d}} \mathrm{AUC}_{0-8}, \mathrm{CV}=93.8 \% \text { during } \\
{ }^{\mathrm{e}} \mathrm{CV}=77.2 \% \text { during attacks } \\
{ }^{\mathrm{f}} \text { Bioavailability }\end{array}$ & $\begin{array}{l}\text { datum not } \\
\text { fferences } \\
\text { ences } \\
\text { g attacks }\end{array}$ & ivailable & \\
\hline
\end{tabular}

dosage, it has been noticed that 10 migraine patients with satisfactory response to sumatriptan absorbed the drug significantly faster and achieved significantly higher plasma levels than patients with unsatisfactory response to oral sumatriptan [44].

The importance of an efficient absorption for the response is also evident if we consider that prokinetic agents may not only be used to eliminate nausea and vomiting, but also to promote absorption [45]. Among migraine patients who had not got adequate relief from triptans, $63 \%$ responded to oral sumatriptan $50 \mathrm{mg}$ combined with metoclopramide $10 \mathrm{mg}$, while only $31 \%$ responded to sumatriptan administered alone [46]. In a small sample size trial, the combination of rizatriptan and trimebutine (another prokinetic agent) was also more effective than rizatriptan alone [47].

\section{Differences in plasma half-life and recurrence}

It is very plausible to assume that the rate of headache recurrence following treatments may be influenced by kinetic properties [48]. On this basis, it has been thought that a longer half-life causes a lower probability of recurrence [49]. Plasma half-life (the time it takes for the blood plasma concentration of a substance to halve) is certainly a parameter which can influence the duration of the action of a drug. In spite of this, plasma half-life can be different from biological half-life (the time it takes to halve pharmacologic activity) due to factors such as tissue accumulation, active metabolites, and strength of receptor interactions. Furthermore, a long plasma half-life can be clinically significant if it assures concentrations which stay for more time within the therapeutic range [48]. Without this information, half-life alone cannot be considered as an indicator of the frequency of recurrence. Frovatriptan, as all triptans, has multiexponential kinetics, but it is the one with the longest half-life (approximately $25-26 \mathrm{~h}$ if calculated in the final phase, up to $48-72 \mathrm{~h}$ after administration) [21]. This drug is also considered one of the triptans with lower frequency of recurrence calculated from $4 \mathrm{~h}$ on [49]. Frovatriptan is distributed in RBCs for $60 \%$ with a link described as reversible and time-dependent [21]. Nevertheless, its concentrations have been determined in whole blood, and the concentrations of the free drug, not bound to RBCs, have not been proved to be clinically effective. In a new analysis of data from previously published studies, it is reported that there were no significant differences in the frequency of relapse within $24 \mathrm{~h}$ after response at $4 \mathrm{~h}$, between frovatriptan $2.5 \mathrm{mg}$ and sumatriptan $100 \mathrm{mg}$, which has a half-life of only $2 \mathrm{~h} \mathrm{[50].}$

In any case, it is not completely clear which triptan is associated to a lower frequency of recurrence. The 
comparison among different studies is not possible, for an endless number of methodological problems (e.g., differences in the study design, the populations used, the characteristics of the attacks, the doses administered, the definition of recurrence, relapse or return, the methods of registration of recurrence, and the presence of recurrence also after the administration of placebo) [12, 49, 51]. Consequently, any result can be interpreted for or against any medication.

\section{Differences in bioavailability and consistency of response}

Bioavailability describes the fraction of an administered dose of unchanged drug that reaches the systemic circulation and it is one of the principal pharmacokinetic properties of drugs. It has been stressed that this parameter has a direct relationship with the intrapatient consistency of response of individual triptans $[11,17,52]$. For sumatriptan, which has an oral bioavailability of only $14 \%$, the consistency of pain relief in two out of three attacks is $64 \%$ and in three out of three attacks, 33\% [53]. For almotriptan, which has instead a higher bioavailability (70\%), pain relief in two out of three attacks is $75 \%$ and in three out of three attacks, 50\% [54]. However, even if rizatriptan has a bioavailability of $40 \%$ (lower than almotriptan), it has a higher consistency of response, since pain relief in two out of three attacks is $86 \%$ and in three out of three attacks, $60 \%$ [55, 56]. Average bioavailability alone does not, therefore, indicate the consistency of response of a specific triptan.

It must be considered that when a medication is administered intravenously, its bioavailability is $100 \%$ and it does not practically vary from a subject to another. When a medication is instead administered via other routes (such as orally), its bioavailability is always lower and it may vary from patient to patient, for different factors such as gastric emptying rate, enzyme induction/ inhibition by other drugs/foods, individual variation in metabolic enzymes, disease state affecting liver metabolism or gastrointestinal function. The presence of all these variables does not allow us to establish and foresee in clinical practice an eventual direct relationship between bioavailability and consistency.

\section{Conclusions}

The changes in kinetic characteristics are not always associated to detectable changes in the relationship between exposition and response to a drug. In the case of

Table 4 Non-pharmacokinetic factors of variability of response to triptans

Factors Description

Dynamic variability

Variability of the mechanisms implicated in the migraine attack

Genetic variability-polymorphisms

Mechanisms of receptor adaptation

Selection of the patient

Placebo effect

Fluctuation of migraine

Prophylactic treatments

Previous therapies

Time of medication administration and severity of the migraine attack
Dynamic variability can be studied in isolated tissues. In this case, a considerable variability in the response to triptans is also observed. For example, EC50 varies 51 times for the vasoconstrictive effect of sumatriptan on human cerebral arteries, 21 times for the effect of rizatriptan, and 69 times for the effect of eletriptan [67]

During the migraine attack various mechanisms are activated. For example, only attacks associated with elevated salivary CGRP levels respond to rizatriptan. This could explain why some patients or attacks are non-triptan responders [68]

STin2 VNTR polymorphism of serotonin transporter gene could be an important genetic factor to confer a higher risk of inconsistent response to triptans in migraine patients [69]

When an excess of mediator is present in the biophase, a process of desensitisation is activated, which makes receptors refractory. This phenomenon can explain why a second tablet of sumatriptan at $2 \mathrm{~h}$ does not increase initial efficacy and does not prevent or delay headache recurrence [70]

The patient must be capable to respond to the drug if we want a response. If the patient takes the triptan for a tension-type headache, the response is improbable, since triptans are not effective in episodic tension-type headache [71]

In clinical practice, a patient's response to an active drug makes us wonder if this patient responds well because of the medication (and its kinetic properties) or because of the placebo effect (caused, for example, by the patient's positive expectations and by the physician who has prescribed the drug) [72]

The course of migraine can vary in years: changes in this disorder are likely to influence the response to triptans [73]

The use of prophylactic medications increases the consistency of response to triptans [10, 24] In individuals with migraine, recent prior opioid use reduces triptan response [74]

The response to triptans is higher and more complete if they are taken early, and when the pain is of mild intensity [26] 
migraine, with oral (and maybe also nasal and rectal) triptans, the importance of kinetic differences is already low for the large variability observed (intersubjets, intrasubjects, gender-related, in healthy volunteers, and in migraine patients outside and during the attack). Furthermore, it is outweighed by the number and importance of non-kinetic sources of variability (Table 4). Choosing an oral triptan according to a mean pharmacokinetic parameter is not an efficient method, since it does not allow choosing, with good probabilities of success, the most appropriate triptan for each patient or to predict which patient will respond to which drug.

Pharmacokinetic parameters are fundamental for the efficacy of a drug, since they influence the arrival at the site of action with the fit concentration. Nevertheless, if their variation range is very large, the behaviour of a certain drug becomes unforeseeable in that specific case. This is why the physician must know the pharmacokinetics of each triptan, but (since he will never have to treat the average patient) also how and why kinetic parameters and the response to the drug can vary in the patient. As a conclusion, understanding variability means understanding the complex relationships among physiology, pathology, pharmacology, and clinical response.

If no new formulations are found allowing more predictable pharmacokinetics, similar problems are very likely to be present also with new classes of drugs. It should, therefore, be useful to become familiar with these issues. The physician's ability to manage uncertainty and unforeseeable aspects of therapy can strongly influence the relationship with the patient and, consequently, the long-term results of migraine treatment.

Conflict of interest None.

\section{References}

1. Adelmand JU, Lewit EJ (2001) Comparative aspects of triptans in treating migraine. Clin Cornerstone 4:53-64

2. Loder E (2010) Triptan therapy in migraine. N Engl J Med 363:63-70

3. Stewart WF, Wood C, Reed MI, Roy J, Lipton RB (2008) Cumulative lifetime migraine incidence in women and men. Cephalalgia 28:1170-1178

4. Brandes JL (2009) Migraine and functional impairment. CNS Drugs 23:1039-1045

5. Tfelt-Hansen P, De Vries P, Saxena PR (2000) Triptans in migraine: a comparative review of pharmacology, pharmacokinetics and efficacy. Drugs 60:1259-1287

6. Saxena PR, Ferrari MD (1989) 5-HT(1)-like receptor agonists and the pathophysiology of migraine. Trends Pharmacol Sci 10:200-204

7. Rapoport AM, Tepper SJ (2001) Triptans are all different. Arch Neurol 58:1479-1480

8. Ferrari MD, Goadsby PJ, Lipton RB, Dodick DW, Cutrer FM, McCrory D, Williams P (2005) The use of multiattribute decision models in evaluating triptan treatment options in migraine. J Neurol 252:1026-1032

9. Pascual J, Mateos V, Roig C, Sanchez-Del-Rio M, Jimenez D (2007) Marketed oral triptans in the acute treatment of migraine: a systematic review on efficacy and tolerability. Headache 47:1152-1168

10. Diener HC, Limmroth V (2001) Advances in pharmacological treatment of migraine. Expert Opin Investig Drugs 10:1831-1845

11. Ferrari MD, Roon KI, Lipton RB, Goadsby PJ (2001) Oral triptans (serotonin 5-HT(1B/1D) agonists) in acute migraine treatment: a meta-analysis of 53 trials. Lancet 358:1668-1775

12. Aurora SK, Dempsey J (2002) Headache recurrence and treatment. Curr Treat Options Neurol 4:335-342

13. Sheftell F, Almas M, Weeks R, Mathew NT, Pitman V, Lipton RB (2010) Quantifying the return of headache in triptan-treated migraineurs: an observational study. Cephalalgia 30:838-846

14. Bigal M, Rapoport A, Aurora S, Sheftell F, Tepper S, Dahlof C (2007) Satisfaction with current migraine therapy: experience from 3 centers in US and Sweden. Headache 47:475-479

15. Dahlöf C, Jones M, Davis K et al (2004) A comparison of preference for and efficacy of tablet formulations of sumatriptan (50 $\mathrm{mg}$ and $100 \mathrm{mg})$, naratriptan $(2.5 \mathrm{mg})$, rizatriptan $(10 \mathrm{mg})$ and zolmitriptan $2.5 \mathrm{mg}$ ) in the acute treatment of migraine. J Headache Pain 5:115-122

16. Ferrari A, Spaccapelo L, Sternieri E (2010) Pharmacoepidemiology of triptans in a headache centre. Cephalalgia 30:847-854

17. Dodick DW, Silberstein S, Dahlöf CG (2002) Is there a preferred triptan? Headache 42:1-7

18. Dixon R, Warrander A (1997) The clinical pharmacokinetics of zolmitriptan. Cephalalgia 17(Suppl 18):18-20

19. Kempsford RD, Baille P, Fuseau E (1997) Oral naratriptan tablets (2.5-1.0 mg) exhibit dose-proportional pharmacokinetics [abstract]. Cephalalgia 17:408

20. Lee Y, Conroy JA, Stepanavage ME, Mendel CM, Somers G, McLoughlin DA, Olah TV, De Smet M, Keymeulen B, Rogers JD (1999) Pharmacokinetics and tolerability of oral rizatriptan in healthy male and female volunteers. $\mathrm{Br} \mathrm{J}$ Clin Pharmacol 47:373-378

21. Easthope SE, Goa KL (2001) Frovatriptan. CNS Drugs 15:969-976

22. Keam SJ, Goa KL, Figgitt DP (2002) Almotriptan: a review of its use in migraine. Drugs 62:387-414

23. Tfelt-Hansen P, Edvinsson L (2007) Pharmacokinetic and pharmacodynamic variability as possible causes for different drug responses in migraine. A comment. Cephalalgia 27:1091-1093

24. Dodick DW (2005) Triptan nonresponder studies: implications for clinical practice. Headache 45:156-162

25. Maas HJ, Danhof M, Della Pasqua OE (2006) Prediction of headache response in migraine treatment. Cephalalgia 26:416-422

26. Valade D (2009) Early treatment of acute migraine: new evidence of benefits. Cephalalgia 29(Suppl 3):15-21

27. Freidank-Mueschenborn E, Fox AW (2005) Resolution of concentration-response differences in onset of effect between subcutaneous and oral sumatriptan. Headache 45:632-637

28. Maas HJ, Spruit MA, Danhof M, Della Pasqua OE (2008) Relevance of absorption rate and lag time to the onset of action in migraine. Clin Pharmacokinet 47:139-146

29. Fox AW (2004) Onset of effect of 5-HT1B/1D agonists: a model with pharmacokinetic validation. Headache 44:142-147

30. Fowler PA, Lacey LF, Thomas M, Keene ON, Tanner RJ, Baber NS (1991) The clinical pharmacology, pharmacokinetics and metabolism of sumatriptan. Eur Neurol 31:291-294

31. Walls C, Lewis A, Bullman J, Boswell D, Summers SJ, Dow A, Sidhu J (2004) Pharmacokinetic profile of a new form of 
sumatriptan tablets in healthy volunteers. Curr Med Res Opin 20:803-809

32. Goadsby PJ (1998) 5-HT $1 \mathrm{~B} / 1 \mathrm{D}$ agonists in migraine: comparative pharmacology and its therapeutic implications. CNS Drugs 10:271-286

33. Duquesnoy C, Mamet JP, Sumner D, Fuseau E (1988) Comparative clinical pharmacokinetics of single doses of sumatriptan following subcutaneous, oral, rectal and intranasal administration. Eur J Pharm Sci 6:99-104

34. Lacey LF, Hussey EK, Fowler PA (1995) Single dose pharmacokinetics of sumatriptan in healthy volunteers. Eur J Clin Pharmacol 47:543-548

35. Tfelt-Hansen P (2007) Parenteral vs. oral sumatriptan and naratriptan: plasma levels and efficacy in migraine. A comment. J Headache Pain 8:273-276

36. Thomsen LL, Dixon R, Lassen LH, Gibbens M, Langemark M, Bendtsen L, Daugaard D, Olesen J (1996) 311C90 (Zolmitriptan), a novel centrally and peripheral acting oral 5-hydroxytryptamine1D agonist: a comparison of its absorption during a migraine attack and in a migraine-free period. Cephalalgia 16:270-275

37. Scott AK (1994) Sumatriptan clinical pharmacokinetics. Clin Pharmacokinet 27:337-344

38. Fowler PA, Thomas M, Lacey LF, Andrew P, Dallas FA (1989) Early studies with the novel 5-HT 1-like agonist GR43175 in healthy volunteers. Cephalalgia 9(Suppl 9):57-62

39. Mojaverian P, Reynolds JC, Ouyang A, Wirth F, Kellner PE, Vlasses PH (1991) Mechanism of gastric emptying of a nondisintegrating radiotelemetry capsule in man. Pharm Res 8:97-100

40. Aurora S, Kori S, Barrodale P, Nelsen A, McDonald S (2007) Gastric stasis occurs spontaneous, visually induced, and interictal migraine. Headache 47:1443-1446

41. Boyle R, Behan PO, Sutton JA (1980) A correlation between severity of migraine and delayed gastric emptying measured by an epigastric impedance method. Br J Clin Pharmacol 30:405-409

42. Dahlöf C (2002) Integrating the triptans into clinical practice. Curr Opin Neurol 15:317-322

43. Dahlöf CG (2005) Non-oral formulations of triptans and their use in acute migraine. Curr Pain Headache Rep 9:206-212

44. Ferrari A, Pinetti D, Bertolini A, Coccia C, Sternieri E (2008) Interindividual variability of oral sumatriptan pharmacokinetics and of clinical response in migraine patients. Eur J Clin Pharmacol 64:489-495

45. Volans GN (1978) Migraine and drug absorption. Clin Pharmacokinet 3:313-318

46. Schulman EA, Dermott KF (2003) Sumatriptan plus metoclopramide in triptan-nonresponsive migraineurs. Headache 43:729-733

47. Krymchantowski AV, Filho PF, Bigal ME (2006) Rizatriptan vs. rizatriptan plus trimebutine for the acute treatment of migraine: a double-blind, randomized, cross-over, placebo-controlled study. Cephalalgia 26:871-874

48. Fox AW, Kori SH (2005) Pharmacokinetic opportunities for combination therapy in migraine. Neurology 64(10 Suppl 2):S21S25

49. Géraud G, Keywood C, Senard JM (2003) Migraine headache recurrence: relationship to clinical, pharmacological, and pharmacokinetic properties of triptans. Headache 43:376-388

50. MacGregor EA, Pawsey SP, Campbell JC, Hu X (2010) Safety and tolerability of frovatriptan in the acute treatment of migraine and prevention of menstrual migraine: Results of a new analysis of data from five previously published studies. Gend Med 7:88-108

51. Dodick DW, Lipton RB, Goadsby PJ, Tfelt-Hansen P, Ferrari MD, Diener HC, Almas M, Albert KS, Parsons B (2008) Predictors of migraine headache recurrence: a pooled analysis from the eletriptan database. Headache 48:184-193
52. Edmeads J (2005) Defining response in migraine: which endpoints are important? Eur Neurol 53(Suppl 1):22-28

53. Sargent J, Kirchner JR, Davis R, Kirkhart B (1995) Oral sumatriptan is effective and well tolerated for the acute treatment of migraine: results of a multicenter study. Neurology 45(Suppl 7): S10-S14

54. Rabasseda X (2001) Almotriptan in the treatment of migraine. Drugs Today 37:5-21

55. Kramer MS, Matzura-Wolfe D, Polis A, Getson A, Amaranemi PG, Solbach MP, McHugh W, Feighner J, Silberstein S, Reines SA, The rizatriptan multiple attack study group (1998) A placebo-controlled crossover study of rizatriptan in the treatment of multiple migraine attacks. Neurology 51:773-781

56. Dahlöf CG, McCarroll LiptonRB, KA KramerMS, Lines CR, Ferrari MD (2000) Within-patient consistency of response of rizatriptan for treating migraine. Neurology 55:1511-1516

57. Cole P, Rabasseda X (2001) Migraine headache treatment with eletriptan, a second-generation serotonin receptor agonist. Drugs Today 37:159-171

58. Buchan P, Keywood C, Wade A, Ward C (2002) Clinical pharmacokinetics of frovatriptan. Headache 42(Suppl 2):S54-S62

59. Fuseau E, Baille P, Kempsford RD (1997) A study to determine the absolute bioavailability of naratriptan [abstract]. Cephalalgia 17:417

60. Cutler NR, Jhee SS, Majumdar AK, McLaughlin D, Brucker MJ, Carides AD, Kramer MS, Matzura-Wolfe D, Reines SA, Goldberg MR (1999) Pharmacokinetics of rizatriptan tablets during and between migraine attacks. Headache 39:264-269

61. Goldberg MR, Lee Y, Vyas KP, Slaughter DE, Panebianco D, Ermlich SJ, Shadle CR, Brucker MJ, McLoughlin DA, Olah TV (2000) Rizatriptan, a novel 5-HT1B/!D agonist for migraine: single- and multiple-dose tolerability and pharmacokinetics in healthy subjects. J Clin Pharmacol 40:74-83

62. McCormack PL, Keating GM (2006) Eletriptan: a review of its use in the acute treatment of migraine. Drugs 66:11291149

63. Dahlof C, Hogenhuis L, Olesen J, Petit H, Ribbat J, Schoenen J, Boswell D, Fuseau E, Hassani H, Winter P (1998) Early clinical experience with subcutaneous naratriptan in the acute treatment of migraine: a dose-ranging study. Eur J Neurol 5:469-477

64. Fuseau E, Webster C, Asgharnejad M et al (1997) Naratriptan oral pharmacokinetics in migraine subjects [abstract]. J Neurol Sci 150(Suppl):S168

65. Sramek JJ, Hussey EK, Clements B, Cutler NR (1999) Oral sumatriptan pharmacokinetics in the migraine state. Clin Drug Investig 17:137-144

66. Cutler NR, Hussey EK, Sramek JJ, Clements BD, Paulsgrove LA, Busch MA, Donn KH (1991) Oral sumatriptan pharmacokinetics in the migrainous state. Cephalalgia 11(Suppl 11):222-223

67. Edvinsson L, Uddman E, Wackenfors A, Davenport A, Longmore J, Malmsjö M (2005) Triptan-induced contractile (5-HT1B receptor) responses in human cerebral and coronary arteries: relationship to clinical effect. Clin Sci 109:335-342

68. Cady RK, Vause CV, Ho TW, Bigal ME, Durham PL (2009) Elevated saliva calcitonin gene-related peptide levels during acute migraine predict therapeutic response to rizatriptan. Headache 49:1258-1266

69. Terrazzino S, Viana M, Floriddia E, Monaco F, Mittino D, Sances G, Tassorelli C, Nappi G, Rinaldi M, Canonico PL, Genazzani AA (2010) The serotonin gene polymorphism Stin2 VNTR confers an increased risk of inconsistent response to triptans in migraine patients. Eur J Pharmacol 641:82-87

70. Ferrari MD, James MH, Bates D, Pilgrim A, Ashford E, Anderson BA, Nappi G (1994) Oral sumatriptan: effect of a second dose, and incidence and treatment of headache recurrences. Cephalalgia 14:330-338 
71. Brennum J, Brinck T, Schriver L, Wanscher B, Soelberg Sorensen P, Tfelt-Hansen P, Olesen J (1996) Sumatriptan has no clinically relevant effect in the treatment of episodic tension-type headache. Eur J Neurol 3:23-28

72. Watkins P (2005) The efficacy of treatment: therapy or therapist? Clin Med 5:309-310

73. Linde M, Mellberg A, Dahlöf C (2006) The natural course of migraine attacks. A prospective analysis of untreated attacks compared with attacks treated with a triptan. Cephalalgia 26:712-721

74. Ho TW, Rodgers A, Bigal ME (2009) Impact of recent prior opioid use on rizatriptan efficacy. A post hoc pooled analysis. Headache 49:395-403 